\title{
Exercise-induced asthma: critical analysis of the protective role of montelukast
}

\author{
This article was published in the following Dove Press journal: \\ Journal of Asthma and Allergy \\ 21 October 2009 \\ Number of times this article has been viewed
}

\author{
Terrence W Carver Jr \\ The Children's Mercy Hospital \\ and Clinics, Kansas City, MO, USA
}

Correspondence: Terrence W Carver Jr The Children's Mercy Hospital and Clinics, 240I Gillham Road, Kansas City, MO, 64108-4619, USA

$\mathrm{Tel}+\mathrm{I} 8162343033$

Fax +I 8168021447

Email twcarver@cmh.edu

\begin{abstract}
Exercise-induced asthma/exercise-induced bronchospasm (EIA/EIB) is a prevalent and clinically important disease affecting young children through older adulthood. These terms are often used interchangeably and the differences are not clearly defined in the literature. The pathogenesis of EIA/EIB may be different in those with persistent asthma compared to those with exercise-induced symptoms only. The natural history of EIA is unclear and may be different for elite athletes. Leukotriene biology has helped the understanding of EIB. The type and intensity of exercise are important factors for EIB. Exercise participation is necessary for proper development and control of EIA is recommended. Symptoms of EIB should be confirmed by proper testing. Biologic markers may also be helpful in diagnosis. Not all exercise symptoms are from EIB. Many medication and nonpharmacologic treatments are available. Asthma education is an important component of managing EIA. Many medications have been tested and the comparisons are complicated. Montelukast is a US Food and Drug Administration-approved asthma and EIB controller and has a number of potential advantages to other asthma medications including short onset of action, ease of use, and lack of tolerance. Not all patients improve with montelukast and rescue medication should be available.
\end{abstract}

Keywords: exercise, asthma, montelukast, Singulair, bronchospasm, leukotrienes

\section{Introduction to EIA and management strategy overview EIA vs EIB}

The use of the term "exercise-induced asthma" (EIA) began during the 1960's. ${ }^{1}$ Subsequently the terms "EIA" and "exercise-induced bronchospasm" (EIB) are often used interchangeably. ${ }^{2}$ However, EIB specifically denotes the reduction in lung function after a standardized exercise test. ${ }^{1,3,4}$ "Exercise-induced bronchoconstriction" is another term that has been used in the literature. ${ }^{5}$ Some clinicians/authors use EIA to describe individuals with known asthma who have bronchoconstriction during exercise ${ }^{6-8}$ However, some use EIA to describe patients that have bronchoconstriction only during exercise, and use EIB to describe patients with asthma that have bronchoconstriction with exercise. ${ }^{9}$ Therefore, the use of the terms "EIA" and "EIB" in the literature is unclear. ${ }^{1}$ For this review I will use the term EIB primarily to indicate bronchospasm with decreased pulmonary function testing following exercise and EIA to indicate those patients with asthma difficulties associated with exercise. 


\section{Overview}

Asthma and allergic rhinitis are closely associated with EIB and are the most common chronic diseases affecting US children. ${ }^{10}$ The prevalence of asthma is increasing ${ }^{11}$ as is EIA. ${ }^{4}$ Exercise is a common trigger for asthmatics, and for some, it is the only trigger. ${ }^{12,13}$ EIA affects patients in all levels of asthma severity, but perhaps with higher prevalence in children with asthma ${ }^{14}$ and many are recognized as having asthma features at rest. ${ }^{15}$ Asthma is heterogeneous ${ }^{16}$ and EIB is likely also heterogeneous. The predominant symptoms of EIA are cough, wheeze, shortness of breath, and chest discomfort associated with exercise. ${ }^{12}$ The physical examination may be normal or consistent with asthma. ${ }^{12}$ The likelihood of different forms of exercise causing asthma symptoms is often referred to its "asthmagenicity." ${ }^{\prime 2}$ For instance, for most asthmatics running is more likely to cause EIA than swimming. More intense exercise is also more likely to lead to asthma symptoms especially if not preceded by a warm-up exercise (see subsequent section on nonpharmacologic treatment of EIB).

EIB may be the result of an overall lack of asthma control $^{13,17}$ and a professional athlete with EIA has a form of occupational asthma ${ }^{18}$ impairing performance. ${ }^{19}$ Exercise is the most common trigger of bronchospasm in children with asthma $^{3,12}$ and worsens quality of life and limits activity. ${ }^{15,20-22}$ Interestingly, the lungs and airways do not respond to exercise training by increasing their capacity similar to the peripheral muscles and the cardiovascular system. ${ }^{4}$ After experiencing a significant EIA event, future exercise-related activities may be limited ${ }^{19}$ and parents of children with asthma have been shown to intentionally or inadvertently restrict their child's activity. ${ }^{22}$ In children with mild-to-moderate asthma, exercise limitation is a primary complaint ${ }^{17}$ and EIA may interfere with activities important for physical and social development. ${ }^{22-25}$ Vilozni and colleagues documented EIA in children as young as three years old. ${ }^{21}$

Regular physical activity is important to health and well-being. Full participation in sporting activities is one of the important goals of asthma management. ${ }^{3,13,22,26}$ Moderate exercise has been shown to stimulate the immune system. ${ }^{27}$ Physical activity is a significant component of daily life in childhood and adolescence, so for those affected with EIA it can be an equally significant problem. ${ }^{3}$ Children and young adults with asthma are more affected by EIB than adults with asthma and therefore EIA is more common for them perhaps because of their increased levels of physical activity. ${ }^{25,28,29}$ Poor perception of EIA symptoms is common and the child may fail to notice the symptoms and others may not take note of the limited performance..$^{21,22}$
The natural history of EIA is unknown. Does asthma resolve if a patient with EIA stops exercising? Does lung function decline more rapidly in a patient with EIA who continues to exercise ${ }^{18}$ These questions remain unanswered. While this is only a brief overview, more comprehensive EIA reviews and guidelines are available. ${ }^{12,30}$

\section{ElA pathogenesis}

In EIB, the airway epithelium is likely disrupted and along with inflammatory cells may be the basis of EIB $^{31}$ (Table 1). EIB may represent a distinct phenotype ${ }^{31}$ and EIB pathogenesis in a chronic asthmatic may be from a different mechanism than a person who only has asthma symptoms with exercise. ${ }^{32}$ Exercise provides multiple stimuli to induce bronchospasm and hyperpnea is thought to be dominant. ${ }^{33}$ Endurance events appear to be higher risk for developing $\mathrm{EIB}^{19,34}$ and the literature remains unclear regarding whether a late-phase response occurs in EIB. ${ }^{35}$

Hyperpnea induces bronchoconstriction through water loss in the "osmotic hypothesis" or airway cooling in the "heat-loss hypothesis." "3,4,12 Because asthma is more common in swimmers compared to other sports, some have suggested a pool chlorine hypothesis as an explanation. ${ }^{36-38}$ However, asthmatics may tolerate swimming better than other activities ${ }^{36}$ and swimming is considered a beneficial whole body exercise. ${ }^{37}$ Ice rink-related athletes are thought to be at higher risk of EIB from airborne ultrafine particulate matter released by ice-resurfacing machines. ${ }^{4}$

Exposure to cold air, allergens, chlorinated pools, or high levels of pollutants may sensitize or irritate the airways. ${ }^{34}$ Risk factors for EIB include family history of atopy, positive skin prick testing, allergic rhinitis and eczema ${ }^{39}$ as well as others and have been reviewed in other works. ${ }^{12}$ Atopy is a major risk factor for EIB in some and controlling rhinitis may improve asthma control. ${ }^{19}$ Exposure to indoor allergens is a risk factor for EIA and immunotherapy is a protective factor. ${ }^{33}$ Some studies have shown elite athletes to be at higher risk of atopy, ${ }^{8}$ but some studies have shown that elite athletes are not at higher risk of allergic sensitization. ${ }^{26}$ Children with human immunodeficiency virus and treated with highly active antiretroviral therapy (HAART) have an increased risk of asthma. ${ }^{40}$

Table I Pathogenesis hypotheses

Osmotic-water loss

Thermal-heat loss

Pool chlorine

Airway sensitization-chemical mediators 
Chemical mediators of an inflammatory cascade including histamine, prostanoids, and leukotrienes are thought to be central in the pathogenesis of EIA. ${ }^{3}$ Of note specifically to this review, the levels of cysteinyl leukotrienes are elevated after exercise in asthmatics with EIB. ${ }^{31}$ Also, eosinophils with a hyperosmolar stimulus generate and release cysteinyl leukotrienes. ${ }^{41}$ Eosinophil levels in blood and sputum have been correlated to the presence and severity of EIB. ${ }^{41}$ The serum concentration of eosinophil cationic protein (ECP), a cytotoxic protein causing desquamation and bronchial epithelial destruction with bronchial hyperactivity, is also higher in asthmatic children with EIB after exercise. ${ }^{42}$ Overall, further research in the causation of EIA is needed. ${ }^{7}$

\section{Confirmation testing}

Exercise tests are commonly utilized to confirm clinical concerns of asthma in children ${ }^{39}$ and history of symptoms alone is not adequate to diagnose EIB. ${ }^{13,32}$ The American Thoracic Society and the European Respiratory Society published guidelines for pulmonary function testing including specific statements for preschool children. ${ }^{43}$ Exercise testing has been specifically addressed as well. ${ }^{44}$ Patients with near-normal airway function at rest may still have significant EIA that limits their ability to exercise. ${ }^{15}$ Airway hyperresponsiveness to exercise suggests a lack of asthma control ${ }^{45}$ and female athletes have greater airway hyperresponsiveness than male athletes. ${ }^{46}$

EIB challenges are subdivided as direct or indirect with direct challenges acting on airway smooth muscle receptors and indirect challenges reflecting the degree of airway inflammation. ${ }^{6}$ Methacholine challenge is the most commonly used direct test. ${ }^{34}$ Indirect tests include exercise, eucapnic voluntary hyperpnea (EVH; also known as isocapnic hyperventilation test), and hyperosmolar aerosols such as hypertonic saline and mannitol acting through the release of mediators. ${ }^{34}$

An exercise challenge is done to reproduce a patient's symptoms and signs and to document pulmonary function changes to confirm or refute the diagnosis of EIA. ${ }^{12}$ A $10 \%-20 \%$ reduction in forced expiratory volume in one second $\left(\mathrm{FEV}_{1}\right)$ or peak expiratory flow (PEF) following exercise and an improvement with a bronchodilator is consistent with EIB. ${ }^{12}$ Exercise challenges are expensive, require significant space, are complex and time intensive, as well as uncomfortable for patients. ${ }^{29,47} \mathrm{~A}$ free running test is the most familiar, most asthmagenic, and least expensive exercise challenge ${ }^{47,48}$ and therefore most convenient. ${ }^{21}$ Inhaling cold, dry air has been shown to be EIB's most potent trigger. ${ }^{3}$ Impulse oscillometry can be used to detect EIB in young children ${ }^{39}$ and EVH may overdiagnose EIB. ${ }^{47}$ The coding and billing for physician services related to EIB testing is reviewed by Pohlig. ${ }^{47}$

\section{Surrogate tests and biologic markers}

Biologic markers measured from the lungs may reflect more accurately EIB related changes compared to other biologic fluids such as urine and blood from less systemic dilution. ${ }^{28}$ The main mediator of neural (nonadrenergic noncholinergic) bronchodilation is thought to be nitric oxide (NO). ${ }^{14}$ In 20 asthmatic children, Nishio and colleagues found that exhaled NO (eNO) was significantly higher in the EIB-positive group than in the EIB-negative group evaluating fall in $\mathrm{FEV}_{1}$ and forced expiratory flow $(\mathrm{FEF})_{25 \%-75 \%}$ following bicycle ergometer exercise testing. ${ }^{49}$ Lex and colleagues studied 85 children with atopic asthma aged 5-16 years and found EIB was not seen with eNO $<25 \mathrm{ppb}$ and that symptom questionnaires were almost as reliable as eNO at ruling out EIB. ${ }^{29}$ Carraro and colleagues evaluated 19 children aged 7-18 years with asthma compared to 14 healthy controls using a treadmill exercise test. ${ }^{28}$ Those with EIB were treated with montelukast for three days and testing was repeated. Measurements of exhaled breath condensate levels of cysteinyl leukotrienes, leukotriene B4, ammonia concentrations, and fraction of eNO were obtained. EIB patients had higher levels of cysteinyl leukotrienes at baseline compared to non-EIB patients and controls. After three days of montelukast, cysteinyl leukotriene levels decreased by a statistically nonsignificant amount and no significant change was noted in fractional eNO either. However, maximal fall in $\mathrm{FEV}_{1}$ did show improvement. In the overall group of children with asthma, the maximal post-exercise fall in $\mathrm{FEV}_{1}$ correlated with the cysteinyl leukotriene level. 8-isoprostane, an oxidative stress marker derived from the free radicalcatalyzed peroxidation of arachidonic acid on plasma membrane phospholipids was measured in the exhaled breath condensate of 46 children and adolescents and baseline levels were higher in the EIB group. ${ }^{14}$ A direct role for chemokines in EIB was not observed in childhood asthma. ${ }^{50}$

\section{Treatment}

Overall asthma management in athletes is similar to nonathletes with asthma. ${ }^{34}$ EIB can be the initial symptom trigger of asthma and the last to resolve with medication. ${ }^{1}$ Exercise tolerance is one of the important measures of asthma control and therefore should be monitored by exercise testing. ${ }^{19,33}$ Asthma medication costs are a large 
part of asthma expenditures. ${ }^{51}$ Many medications have been used in the treatment of EIA and have included albuterol, salmeterol, formoterol, montelukast, ipratropium bromide, calcium channel blockers, inhaled furosemide, theophylline, cromolyn, nedocromil, and inhaled corticosteroids. . $^{8,19,23-25,48}$ Choice between these agents is based on onset, efficiency, safety profile, ease of use, compliance, cost, and duration of action. . $^{12,13,16,52}$

Asthma education to develop and improve self management skills should be included in overall asthma management. ${ }^{22,30}$ Unfortunately, school policies may not facilitate asthma management and may lead to opting out of exercise. ${ }^{22}$ Parents, children, teachers, coaches, and trainers require asthma education regarding exercise participation, asthma medication adjustment, and how to distinguish between normal physiologic and asthma exercise limitations. ${ }^{22}$

\section{Therapeutic use exemptions}

Some have been concerned that athletes without asthma have also been using $\beta_{2}$-agonists. ${ }^{34}$ Doping is defined as the use of forbidden substances and methods intending to improve an athlete's performance. The World Anti-Doping Agency has a prohibited list of medications as well as therapeutic use exemptions for medications including $\beta_{2}$-agonists and glucocorticosteroids. ${ }^{53}$ From 2003-2008, 868 therapeutic use exemptions for $\beta_{2}$-agonists were received by the International Association of Athletics Federations and 80\% were approved. ${ }^{34}$ No ergogenic effects of inhaled $\beta_{2}$-agonists or inhaled steroids have been demonstrated. ${ }^{8} \beta_{2}$-agonists and inhaled corticosteroids are not thought to improve an athlete's performance outside of improving asthma control. ${ }^{4}$ The use of inhaled $\beta_{2}$-agonists by athletes has increased and perhaps were previously underused. ${ }^{34}$ The International Olympic Committee has recommended a diagnosis based on symptoms be confirmed with pulmonary function testing. ${ }^{34}$

\section{Nonpharmacologic treatment of EIB}

Reducing asthma trigger exposures and warm-up pre-exercise is important in preventing EIB. ${ }^{1,11,30}$ Breathing through the nose during exercise ${ }^{1}$ and a face mask when exercising in cold air may be helpful. ${ }^{8,19,34}$ A cool-down exercise may also be helpful in reducing EIB episodes. ${ }^{1,19}$ Aerobic exercise training reduced bronchial hyperresponsiveness and the improvements were enhanced with concomitant montelukast. ${ }^{54}$ Patients with EIA should be cautioned not to exercise when their asthma is not under control. ${ }^{12}$

Avoiding training in suboptimal environments should reduce airway penetration of harmful factors during the high ventilation demands of intense exercise. ${ }^{34}$ Also reducing chlorine derivatives in swimming pools, ozone, and particulate matter may also be helpful in preventing EIB. ${ }^{34}$ Allergen avoidance in sensitized individuals is recommended. ${ }^{8}$ Diet may also influence $\mathrm{EIB}^{32}$ and increasing components such as omega-3 polyunsaturated fatty acids and antioxidant intake as well as reducing sodium may be helpful. ${ }^{8}$ Increasing vitamin $\mathrm{C}$ intake may decrease EIB as well. ${ }^{32}$

\section{Precautions}

The differential diagnosis of EIB has been reviewed in multiple studies. ${ }^{4,8,12}$ Not all dyspnea associated with exercise is from EIB $^{12}$ and not all dyspnea when exercising in cold air is asthma either. ${ }^{55}$ For instance exercising in a cold environment reduces exercise capacity independent of EIB although the cold environmental conditions aggravated the effects of EIB. ${ }^{56}$

\section{Leukotriene biology}

Exercise physical stress induced transcriptional changes, specifically in the leukotriene pathway have been shown to be enhanced following exercise and may play a role in EIB. ${ }^{2}$ Concentrations of cysteinyl leukotrienes are higher in asthmatic children with $\mathrm{EIB}^{3}$ and are thought to mediate the immediate reduction in airway caliber. ${ }^{20}$ Leukotrienes are a family of polyunsaturated eicosatetraenoic acids formed from the phospholipid layer. ${ }^{11}$ The two classes of leukotrienes are cysteinyl $\left(\mathrm{LTC}_{4}, \mathrm{LTD}_{4}, \mathrm{LTE}_{4}\right)$ and noncysteinyl $\left(\mathrm{LTB}_{4}\right) .{ }^{11}$ The cysteinyl leukotrienes all contain a thioether-linked peptide: glutathione in LTC4, cysteinyl-glycine in LTD4, and cysteine in LTE4. ${ }^{51}$

Cysteinyl leukotrienes are derivatives of the 5-lipoxygenase pathway of arachidonic acid metabolism and are one of the important mediators of airway inflammation including a role in the pathogenesis of EIA. ${ }^{3}$ Phospholipase $\mathrm{A}_{2}$ catalyzes the release of arachidonic acid from membrane phospholipids and the subsequent enzyme actions are reviewed by Riccioni and colleagues. ${ }^{2,51}$ The cysteinyl leukotriene synthesis pathway requires a series of sequential enzyme actions from 5-lipoxygenase, 5-lipoxygenase-activating protein, and leukotriene $\mathrm{C}_{4}$ synthase. ${ }^{57}$ Chromosome $5 \mathrm{q} 35$ encodes for the key enzyme leukotriene $\mathrm{C}_{4}$ synthase which converts leukotriene $\mathrm{A}_{4}$ to $\mathrm{C}_{4}{ }^{57}$ Cysteinyl leukotrienes are released from activated inflammatory cells including mast cells and eosinophils, ${ }^{3,41}$ basophils, ${ }^{58}$ neutrophils, macrophages, epithelial cells, and vascular endothelial cells. ${ }^{11}$

Cysteinyl leukotrienes act on type I (Cys-LT $\left.\mathrm{T}_{1}\right)$ receptors as a pro-inflammatory mediator with numerous local and 
systemic effects including bronchoconstriction and increased airway hyperresponsiveness, decreased activity of respiratory cilia, increased mucus secretion, increased venopermeability with plasma exudation, vasoconstriction, promotion of eosinophil migration into the airway mucosa, and airway smooth muscle proliferation..$^{3,23,57-60}$ The Cys-LT 1 receptor gene maps to the $\mathrm{X}$ chromosome. ${ }^{57}$ Leukotrienes are 100 to 1,000 times more effective than histamine in inducing bronchospasm, ${ }^{3,59}$ and were previously known as the slowreacting substance of anaphylaxis. ${ }^{23}$ Ten to $20 \%$ of cysteinyl leukotrienes produced are released into the urine. ${ }^{3}$ In asthmatic patients, the urinary excretion of leukotriene $\mathrm{E}_{4}$ increases after exercise. ${ }^{61}$ Even high doses of oral steroids do not change urinary or airway secretion concentrations of leukotrienes. ${ }^{11}$

\section{Pharmacology, mode of action, and pharmacokinetics of montelukast Clinical pharmacology/biochemistry of montelukast}

Montelukast is rapidly absorbed following oral administration with peak plasma concentrations in 2.6-4 hours and a mean bioavailability of $58 \%-73 \%,{ }^{3,59}$ which is generally noted to be higher in chewable tablets. ${ }^{59}$ No dose-response relationship was observed down to a $10 \mathrm{mg}$ once daily dose in adults and the children's dose was chosen to provide a similar overall drug exposure anticipating similar efficaciousness. ${ }^{59}$ Absorption and pharmacokinetics is not much affected by meals or by the time of day administered, respectively. ${ }^{59,60}$ Steady state was reached on day 2 of administration. ${ }^{59}$ The mechanism of action is through high affinity and selectively binding to the Cys-LT 1 receptor without agonist activity. ${ }^{62}$ Gender and advanced age do not significantly influence montelukast pharmacokinetics. ${ }^{59,62}$ Montelukast is extensively bound to plasma proteins with a volume of distribution average of 8-11 liters, minimal distribution across the blood-brain barrier, and minimal tissue concentrations 24 hours after administration..$^{59,62}$ Montelukast is extensively metabolized in humans and is similar in pediatric and adult subjects. ${ }^{59}$ Metabolites are excreted in bile with minimal amounts in plasma and $0.2 \%$ recoverable in urine. ${ }^{59}$

Once daily dosing at bedtime was chosen based on higher plasma levels at night when the circadian variation for asthma-related airway obstruction tends to be worse ${ }^{59}$ and when there may be a higher concentration of alveolar-tissue CD4 ${ }^{+}$lymphocytes. ${ }^{63}$ Pajaron-Fernandez and colleagues found no statistical difference in exercise challenge results when comparing morning vs evening montelukast dosing in 24 children aged 6-14 years, but showed better outcomes in some children with evening dosing. ${ }^{63}$ Medication-induced tolerance to the bronchoprotective effect over time has not been noted. ${ }^{3}$

\section{Singulair overview}

Singulair (Merck \& Co., Inc., Whitehouse Station, NJ, USA) is an orally active, selective leukotriene receptor antagonist medication for treating asthma and allergic rhinitis. ${ }^{3,62}$ Montelukast may also inhibit 5-lipoxygenase. ${ }^{2}$ Both single and multidose studies in adults and children have shown protection against EIA. ${ }^{3}$ Singulair is available in multiple oral formulations including a $10 \mathrm{mg}$ film-coated tablet, $4 \mathrm{mg}$ and $5 \mathrm{mg}$ chewable tablets, and $4 \mathrm{mg}$ oral granules. ${ }^{3}$ Singulair is administered $10 \mathrm{mg}$ once daily to adults, $5 \mathrm{mg}$ once daily to children aged 6-14 years, and $4 \mathrm{mg}$ once daily to children aged 2-5 years for asthma treatment. ${ }^{59,62}$ In April 2007, the US Food and Drug Administration (FDA) approved montelukast as a single-dose preventative for EIB in patients aged 15 years or older. ${ }^{17}$ The response to asthma medications is variable, ${ }^{16}$ including montelukast. ${ }^{32}$ Predicting by genotype which patients will be poor or better responders to montelukast has been studied,,$^{57,64,65}$ but no clear clinical recommendations have been made.

\section{Efficacy studies in children, adolescents, and adults Complications in reviewing studies}

Comparisons of the outcomes of studies evaluating the effectiveness of montelukast is complicated by many factors including the inclusion criteria of the studied group, particularly how the authors defined EIA and/or EIB. Other specific variations include age of the patients, subtype of asthma (eg, EIA only, intermittent, severity class of persistence), concomitant medications allowed (eg, inhaled corticosteroids, long- and short-acting $\beta_{2}$-agonists, antihistamine), control at the time of the exercise challenge(s), aspirin sensitivity, severity of the allergic component, overall diet (eg, caffeine intake, omega-3, vitamin C), seasonal changes over the study period, as well as others were found in reviewing the studies. The end points and the comparisons made were also variable. Protocols of timing (eg, relative to medication dosage, time of day) and type of exercise challenge (treadmill, bicycle, free running) and duration of dosing were also variables making comparisons difficult. Small numbers involved in many studies led to limitations.

Various measurements have evaluated the effectiveness of EIB prevention. These measurements have included: reduction 
in the area under the $\mathrm{FEV}_{1}$ curve, the maximal decrease in post-exercise $\mathrm{FEV}_{1}$, time from the maximal decrease in $\mathrm{FEV}_{1}$ to return to within $5 \%$ or $10 \%$ of pre-exercise values, number of patients who required $\beta_{2}$-agonist rescue, asthma symptom score, and percentage of those protected. No end point is considered clearly the best. Many studies that used more than one end point sometimes found statistical significance with one or some, but not all end points. Some have suggested that an improvement in percentage decrease in $\mathrm{FEV}_{1}$ of $50 \%$ or greater relative to placebo-related decrease can be defined as clinically significant. ${ }^{61}$ In the following themed comparisons, I have arranged most of the studies chronologically.

\section{Montelukast compared to placebo}

Bronsky and colleagues studied 27 patients by exercise challenge 20-24 hours and 32-36 hours after montelukast $0.4 \mathrm{mg}$ up to $50 \mathrm{mg}$ vs placebo. ${ }^{58}$ They found montelukast 10 and $50 \mathrm{mg}$ protected against EIB compared to placebo at 20-24 hours post-dose and only slight nondose-related effects were observed at 32-36 hours post-dose. Kemp and colleagues compared montelukast to placebo in 27 children aged 6-14 years and found improvements in EIB in the montelukast group..$^{23}$ In a 12-week study, Leff and colleagues compared montelukast to placebo in 110 patients aged 15-45 years by treadmill exercise challenge and found EIB protection with montelukast. ${ }^{45}$ No protective or rebound effects were found two weeks after treatment was stopped. Melo and colleagues studied 22 patients with a mean age of 12.6 years on a stationary bicycle and found less deterioration in lung function with montelukast compared to placebo including a late phase response in the minority of patients with a dual response. ${ }^{35} \mathrm{Kim}$ and colleagues enrolled 64 children aged 8-14 years to compare eight weeks of montelukast to placebo in an outdoor free running challenge and found the asthma symptom score significantly improved for the montelukast group. ${ }^{48}$ This improvement persisted after an additional eight weeks of placebo. de Benedictis and others studied 32 children aged 6-12 years for four weeks to compare montelukast to placebo by exercise challenge at days 3, 7, and 28 and found improvement with montelukast independent of concomitant inhaled steroids and without evidence of tolerance. ${ }^{66}$

In their study of almost 50 patients, Pearlman and colleagues showed improvement in protection from EIB by exercise challenge at two, 12, and 24 hours after dosing with a single dose of montelukast compared to placebo. ${ }^{61}$ However, in their study of 19 patients aged $7-13$ years Peroni and colleagues found protection with montelukast vs placebo with exercise challenge at 12 hours, but not at two or 24 hours following single-dose therapy. ${ }^{24}$ These authors point out that the dose of montelukast was received in the morning, that all study patients were on inhaled corticosteroids, and that a placebo effect has been documented. In a Merck-supported study by Philip and colleagues, montelukast was compared to a placebo in a group of patients aged 15-45 years two hours after a single dose using a treadmill exercise challenge and found significantly more patients receiving montelukast were protected from EIB. ${ }^{67}$ This protection was also noted at 12 and 24 hours postdose.

\section{Montelukast compared to long-acting $\beta_{2}$-agonists}

In a Merck grant-supported study by Villaran and colleagues, 197 patients aged 14-45 years were evaluated to compare montelukast and salmeterol over an eight-week time frame and improvements in both treatment groups was found, but montelukast had the greater effect. ${ }^{68}$ Patients treated with concomitant inhaled corticosteroids showed the same effect as those not on inhaled corticosteroids and tolerance to bronchoprotection was not prevented by concomitant inhaled corticosteroids. In a Merck-funded trial, Edelman and others studied 177 patients aged 15-45 years to compare eight weeks of montelukast to salmeterol. ${ }^{15}$ Within three days both groups showed EIB improvements. However, a loss of bronchoprotective effect was noted in the salmeterol groups at four and eight weeks whereas the montelukast effect was maintained. Storms and colleagues compared montelukast, salmeterol, and placebo over a four-week treatment period in patients aged 15-45 years. ${ }^{69}$ They observed a number of findings, including maximal post-albuterol rescue $\mathrm{FEV}_{1}$ percent-predicted values improved in montelukast and placebo groups, but not in salmeterol with the maximum $\mathrm{FEV}_{1}$ lowest in the salmeterol group. Patients treated with montelukast had significantly greater alleviation of EIB compared to placebo but the salmeterol group did not. The authors pointed out that concerns in the salmeterol group regarding long-acting $\beta_{2}$-agonists decreased the effects of short-acting $\beta_{2}$-agonists and tachyphylaxis with downregulation of airway smooth muscle receptor numbers. Uncoupling of intracellular signaling may occur even with concomitantly administered inhaled corticosteroids. Steinshamm and colleagues compared montelukast to salmeterol in 18 adults with EIB and concluded that montelukast has a favorable effect on gas exchange at moderate exercise compared to salmeterol. ${ }^{70}$ They also pointed out the suggestion that regular use of salmeterol leads to a decrease in rescue response 
to short-acting $\beta_{2}$-agonists after exercise. Salmeterol and formoterol provide EIB protection after a single dose for up to 12 hours but their protective duration lessens when given regularly. ${ }^{61}$ In a Merck protocol, Philip and colleagues compared single-dose montelukast or salmeterol in 47 patients aged 14-45 years by treadmill exercise challenge and found significant EIB protection within two hours of dosing and duration of at least 24 hours for montelukast. ${ }^{52}$ The efficacy was similar in a magnitude to $50 \mu \mathrm{g}$ of inhaled salmeterol with a longer duration. Stelmach and colleagues studied 91 patients aged 6-18 years with EIB and allergies comparing budesonide/formoterol, budesonide/montelukast, montelukast, budesonide, or matching placebo for eight weeks. They found the protective effect against treadmill exercise challenge better with montelukast and budesonide/ montelukast by comparison. ${ }^{9}$ They recommended that montelukast should be added to control EIB in children even if on low-dose inhaled steroid therapy.

The International Olympic Committee and others recommend against using LABAs as monotherapy. ${ }^{11,30,34}$ In an editorial by Dr Miles Weinberger, he states "clinicians would be wise to add LABAs selectively...so as to identify the occasional patient in whom the induced tolerance results in decreased clinical response to the $\beta_{2}$-agonist inhaler that the patient uses for rescue and before exercise." ${ }^{\text {71 }}$ Szefler has made similar recommendations. ${ }^{40}$

\section{Montelukast compared to short-acting $\beta_{2}$-agonists}

Raissy and colleagues studied 11 patients $7-17$ years old with mild asthma with a treadmill exercise challenge comparing 3-7 days of montelukast or placebo with albuterol MDI pre-exercise and found the albuterol superior in preventing EIB. ${ }^{17}$ Hancox and colleagues evaluated a group of patients aged18-50 years with EIB by treating them with salbutamol or matching placebo for one week and found those treated with scheduled salbutamol had worsened EIB after dry-air cycle ergometer exercise challenge. ${ }^{72}$ In addition, the $\mathrm{FEV}_{1}$ remained significantly lower throughout the post-exercise salbutamol doseresponse rescue in those treated with scheduled salbutamol. The authors were concerned that patients with EIA treated with regular or frequent $\beta$-agonist medications will have worsening exercise symptoms and a reduced response to $\beta$-agonist rescue. The frequency, dose, and duration to develop these effects are unknown. A combination of receptor downregulation and proinflammatory mechanisms were postulated as causes.
The International Olympic Committee has stated that although " $\beta_{2}$-agonists are likely to remain the most effective bronchodilators available in the foreseeable future" they "should be reserved for occasional use and breakthrough symptoms." 30 Tolerance to $\beta_{2}$-agonists, usually only partial, is a concern, increasing the airway sensitivity to bronchoconstriction to exercise and allergen stimuli. ${ }^{34}$ The International Olympic Committee and others recommend against regular/frequent short-acting $\beta_{2}$-agonist use as sole therapy for athletes with asthma. ${ }^{34}$

\section{Montelukast compared to mast cell stabilizers}

A study by Lecheler and colleagues compared a fixed combination of disodium cromoglycate plus reproterol (DSCG/REP) to montelukast in a group of children aged 11-18 years and found that DSCG/REP before exercise was superior in preventing EIA. ${ }^{73}$ Significant limitations in this study are noted including small numbers and an open design among others.

\section{Montelukast compared to inhaled corticosteroids}

Vidal and others compared montelukast to budesonide in 20 patients with EIA and found that budesonide provided improved protection to exercise challenge on a treadmill compared to montelukast in 16 patients $(80 \%)$, but better protection with montelukast in the remaining four patients $(20 \%) .{ }^{20}$ They concluded with the recommendation that both medications be tested in each patient prior to the final decision. Formoterol combined with budesonide was similar to budesonide alone suggesting little additional effect after eight weeks of treatment. ${ }^{9}$

\section{Montelukast compared with loratadine}

Peroni and colleagues compared placebo, loratadine, montelukast, and combination montelukast and loratadine in a single-dose test in 19 allergic-asthma children and found no statistically significant additive effect using the combination compared to montelukast alone. ${ }^{74} \mathrm{H} 1$-antihistamines have been found to have minimal EIB effects. ${ }^{19}$

\section{Montelukast compared to other leukotriene modifiers}

Zileuton, a 5-lipoxygenase inhibitor; MK-571, pranlukast, cinalukast, zafirlukast leukotriene receptor antagonists; and iralukast, an LTD4/LTE4 antagonist have produced both subjective and objective improvements in asthma 
patients. ${ }^{19,23,48,75}$ Coreno and colleagues compared salmeterol, montelukast, zafirlukast, zileuton, and placebo in 10 patients using a cycle ergometer and breathing frigid air and found that all of the leukotriene-modifying drugs inhibited EIA however zileuton was less potent and shorter acting. ${ }^{76}$

\section{Montelukast in aspirin-sensitive patients}

Aspirin sensitive asthmatics are characterized by cysteinyl leukotriene overproduction and excrete high amounts in their urine. ${ }^{77}$ They have overexpression of $\mathrm{LTC}_{4}$ synthase on bronchial biopsy and a variant of allele $\mathrm{C}$ is more common in severely effected aspirin-sensitive patients. ${ }^{77}$ Mastalerz and others studied 19 aspirin-sensitive asthmatics by exercise challenge and found that a single dose of montelukast attenuated or prevented EIB in the majority compared to placebo. $^{77}$

\section{Montelukast limitations/concerns/ safety/tolerability}

Not all patients taking montelukast are protected from EIA, ${ }^{3}$ with protection ranges typically from $50 \%-80 \% .{ }^{48}$ As noted previously in the Singulair overview section, no biologic markers clearly identify antileukotriene medication responders from nonresponders. ${ }^{3}$ The $4 \mathrm{mg}$ and $5 \mathrm{mg}$ preparations contain phenylalanine and patients with phenylketonuria should avoid them. ${ }^{62}$ Treatment of airway inflammation with ICS has been shown to improve oxygenation and exercise performance due to increased alveolar ventilation and improved pulmonary gas exchange efficiency. ${ }^{78}$ Similar studies with montelukast are not found in the literature.

\section{Side effects}

Most studies suggest leukotrienes receptor antagonists are well tolerated ${ }^{11}$ and montelukast is rated pregnancy category B by the US FDA. ${ }^{60,62}$ It is unknown if montelukast is excreted in human milk. ${ }^{62}$ No evidence of dose-limiting toxicity has been noted. ${ }^{59}$ Montelukast was not associated with growth rate reduction as has been seen in inhaled corticosteroids. ${ }^{11}$ No clinically important drug interactions with montelukast have been identified. ${ }^{59,60,62}$ However zileuton may affect other drugs' metabolism and also has been associated with liver dysfunction. ${ }^{60}$ Churg-Strauss syndrome has been associated with zafirlukast, but not montelukast. ${ }^{11}$ Physicians are recommended to remain alert for eosinophilia, vasculitic rash, and other symptoms. ${ }^{62}$ Montelukast has a wide safety margin with no dosage adjustment for renal insufficiency or for mild to moderate hepatic insufficiency. ${ }^{59}$ Liver dysfunction has also been associated with zafirlukast so monitoring liver function has been recommended. ${ }^{60}$ Post-marketing experiences have further documented potential side effects including a relatively recent report of an adolescent patient suicide while treated with montelukast. ${ }^{40,62}$

\section{Clinical usage based on patient- focused perspectives and clinical data}

Approximately one third of all maintenance therapy prescriptions for asthma are for leukotriene inhibitors thought to be related to ease of use and dosing, lack of side effects, and efficacy ${ }^{60}$ (Table 2). Montelukast can be used intermittently since effectiveness is noted after a single dose. ${ }^{3}$ However, it may be best suited as a daily controller for patients with poor inhaler technique or poor compliance, patients concerned with inhaled steroid effects, or patients with EIB, especially if they continue to have inadequate protection from short-acting $\beta_{2}$-agonists. ${ }^{16,60}$ Some clinicians use montelukast particularly for children with activity levels that are frequent, but at irregular intervals ${ }^{3,7}$ throughout the day, which makes it hard to anticipate pre-exercise $\beta_{2}$-agonists and perhaps leading to regular and too frequent usage. ${ }^{61}$ Given that regular $\beta_{2}$-agonists adversely affects EIB, some clinicians suggest that they be "prescribed with care particularly in patients with prominent exercise symptoms." 72 As a guideline, some authors have suggested that those with EIA more than once or twice a week might benefit with use of an anti-inflammatory treatment. ${ }^{20}$

Inhaled corticosteroids have been shown to be more effective than montelukast in several measures of asthma control, ${ }^{16}$ but this may be different in regards to EIB. Increasing from a low dose of an inhaled corticosteroid for uncontrolled asthma results in marginal improvement in efficacy and may lead to unwanted side effects. Adding a long-acting $\beta_{2}$-agonist or leukotriene receptor antagonist to improve control is recommended..$^{69}$ In EIA patients, montelukast may be advantageous to long-acting $\beta_{2}$-agonist add-on therapy. ${ }^{69}$

Table 2 Montelukast advantages

Large treatable age range and multiple dosing forms

Once a day

Taken by mouth, easy to swallow or a tasty chewable

Improves EIB in the majority of patients

Lack of tolerance

Good safety profile

Abbreviation: EIB, exercise-induced bronchospasm. 
The ease of a daily oral tablet at bedtime encourages adherence compared to other asthma medications. ${ }^{10,16,20}$ In addition, the choice to use long-acting $\beta_{2}$-agonist as add on treatment for asthma control may adversely affect EIA. ${ }^{69}$ Lastly the lack of tolerance may make montelukast preferential to others. ${ }^{3}$ Neither montelukast nor salmeterol provided complete bronchoprotection and therefore prophylactic use of a short-acting $\beta_{2}$-agonist may be necessary ${ }^{15}$ and should be available for breakthrough symptoms. Finding the individually correct therapeutic balance of efficacy, tolerability, adherence, and ease of use is left to the clinician and caregiver to achieve. ${ }^{16}$

\section{Conclusions}

EIA is an important clinical disease for patients young and old. The pathogenesis of EIA remains uncertain, but the biology is becoming more clearly understood. Patient symptoms lead the clinician to provide confirmatory testing and treatment. Many treatment options are available and extrapolating study data to an individual patient is complicated. Clinically, montelukast is a helpful medication for many patients with EIB and is typically well tolerated.

\section{Disclosures}

The author reports no conflicts of interest in this work. The author thanks Donna M Moore, Ashley L Pore, and Nicole Curless for administrative assistance.

\section{References}

1. Randolph C. Exercise-induced bronchospasm in children. Clin Rev Allergy Immunol. 2008;34:205-216.

2. Hilberg T. Etiology of exercise-induced asthma: physical stress-induced transcription. Curr Allergy Asthma Rep. 2007;7(1):27-32.

3. de Benedictis FM, Vaccher S, de Benedictis D. Montelukast sodium for exercise-induced asthma. Drugs Today (Barc). 2008;44(11): 845-855.

4. Carlsen KH, Anderson SD, Bjermer L, et al. Exercise-induced asthma, respiratory and allergic disorders in elite athletes: epidemiology, mechanisms and diagnosis: part I of the report from the Joint Task Force of the European Respiratory Society (ERS) and the European Academy of Allergy and Clinic Immunology (EAACI) in cooperation with GA²LEN. Allergy. 2008;63(4):387-403.

5. Kennedy JL, Jones SM. Effect of different antiasthmatic treatments on exercised-induced bronchoconstriction in children with asthma. Pediatrics. 2008;122:S220.

6. Rundell KW, Slee JB. Exercise and other indirect challenges to demonstrate asthma or exercise-induced bronchoconstriction in athletes. J Allergy Clin Immunol. 2008;122(2):238-246.

7. Sánchez-Solís, M. Exercise-induced asthma, still much to learn. Allergol Immunopathol (Madr). 2008;36(3):121-122.

8. Billen A, Dupont L. Exercise-induced bronchoconstriction and sports. Postgrad Med J. 2008;84(996):512-517.

9. Stelmach I, Grzelewski T, Majak P, Jerzynska J, Stelmach W, Kuna P. Effect of different antiasthmatic treatments on exercise-induced bronchoconstriction in children with asthma. J Allergy Clin Immunol. 2008;121(2):383-389.
10. Storms W. Update on montelukast and its role in the treatment of asthma, allergic rhinitis and exercise-induced bronchoconstriction. Expert Opin Pharmacother. 2007;8(13):2173-2187.

11. Ribeiro JD, Toro AA, Baracat EC. Antileukotrienes in the treatment of asthma and allergic rhinitis. J Pediatr. 2006;82 Suppl 5:S213-S221.

12. Carver TW. Pediatric athletic asthmatics. Curr Allergy Asthma Rep. 2008;8:500-504.

13. National Heart Lung and Blood Institute. Guidelines for the diagnosis and management of asthma. Available from: http://www.nhlbi.nih.gov. Cited 2009 Jul 22.

14. Barreto M, Villa MP, Olita C, et al. 8-Isoprostane in exhaled breath condensate and exercise-induced bronchoconstriction in asthmatic children and adolescents. Chest. 2009;135(1):66-73.

15. Edleman JM, Turpin JA, Bronsky EA, et al. Oral montelukast compared with inhaled salmeterol to prevent exercise-induced bronchoconstriction. A randomized, double-blind trial. Ann Intern Med. 2000;132(2):97-104.

16. Wahn U, Dass B. Review of recent results of montelukast use as a monotherapy in children with mild asthma. Clin Ther. 2008;30 Theme Issue:1026-1035.

17. Raissy HH, Harkins M, Kelly F, Kelly HW. Pretreatment with albuterol versus montelukast for exercise-induced bronchospasm in children. Pharmacotherapy. 2008;28(3):287-294.

18. Burge PS, Robertson A. Exercise-induced asthma, respiratory and allergic disorders in elite athletes. Allergy. 2008;63(8):1084.

19. Schwartz LB, Degado L, Craig T, et al. Exercise-induced hypersensitivity syndromes in recreational and competitive athletes: a PRACTALL consensus report (what the general practitioner should know about sports and allergy). Allergy. 2008;63:953-961.

20. Vidal C, Fernández-Ovide E, Piñeiro J, Nuñez R, González-Quintela A. Comparison of montelukast versus budesonide in the treatment of exercise-induced bronchoconstriction. Ann Allergy Asthma Immunol. 2001;86:655-658.

21. Vilozni D, Bentur L, Efrati O, et al. Exercise challenge test in 3- to 6-year-old asthmatic children. Chest. 2007;132(2):497-503.

22. Williams B, Powell A, Hoskins G, Neville R. Exploring and explaining low participation in physical activity among children and young people with asthma: a review. BMC Fam Pract. 2008;9:40.

23. Kemp JP, Dockhorn RJ, Shapiro GG, et al. Montelukast once daily inhibits exercise-induced bronchoconstriction in 6- to 14-year-old children with asthma. J Pediatr. 1998;133(3):424-428.

24. Peroni DG, Piacentini GL, Ress M, Bodini A, Loiacono A, Boner AL. Time efficacy of a single dose of montelukast on exercise-induced asthma in children. Pediatr Allergy Immunol. 2002;13(6):434-437.

25. Pearlman D, Milgrom H, Till D, Ziehmer B. Effect of formoterol fumarate treatment on exercise-induced bronchoconstriction in children. Ann Allergy Asthma Immunol. 2006;97(3):382-388.

26. Ventura MT, Cannone A, Sinesi D, et al. Sensitization, asthma and allergic disease in young soccer players. Allergy. 2009;64(4):556-559.

27. Rong C, Bei H, Yun M, Yuzhu W, Mingwu Z. Lung function and cytokine levels in professional athletes. $J$ Asthma. 2008;45(4):343-348.

28. Carraro S, Corradi M, Zanconato S, et al. Exhaled breath condensate cysteinyl leukotrienes are increased in children with exercise-induced bronchoconstriction. J Allergy Clin Immunol. 2005;115(4):764-770.

29. Lex C, Dymek S, Heying R, Kovacevic A, Kramm CM, Schuster A. Value of surrogate tests to predict exercise-induced bronchoconstriction in atopic childhood asthma. Pediatr Pulmonol. 2007;42:225-230.

30. International Olympic Committee. IOC consensus statement on asthma in elite athletes. January 2008. Available from: http://multimedia. olympic.org/pdf/en_report_1301.pdf. Cited 2009 Jul 22.

31. Hallstrand TS, Henderson WR. Role of leukotrienes in exercise-induced bronchoconstriction. Curr Allergy Asthma Rep. 2009;9(1):18-25.

32. Parsons JP, Mastronarde JG. Exercise-induced asthma. Curr Opin Pulm Med. 2009;15(1):25-28.

33. Martin-Muñoz MF, Pagliara L, Antelo MC, et al. Exercise-induced asthma in asthmatic children. Predisposing factors. Allergol et Immunopathol. 2008;36(3):123-127. 
34. Fitch KD, Sue-Chu M, Anderson SD, et al. Asthma and the elite athlete: summary of the International Olympic Committee's consensus conference, Lausanne, Switzerland, January 22-24, 2008. J Allergy Clin Immunol. 2008;122(2):254-260.

35. Melo RE, Solé D, Naspitz CK. Exercise-induced bronchoconstriction in children: montelukast attenuates the immediate-phase and late-phase responses. J Allergy Clin Immunol. 2003;111(2):301-307.

36. Goodman M, Hays S. Asthma and swimming: a meta-analysis. J Asthma. 2008;45:639-647.

37. Uyan ZS, Carraro S, Piacentini G, Baraldi E. Swimming pool, respiratory health, and childhood asthma: should we change our beliefs? Pediatr Pulmonol. 2009;44:31-37.

38. Bernard A, Nickmilder M, Voisin C. Outdoor swimming pools and the risks of asthma and allergies during adolescence. Eur Respir J. 2008;32(4)979-988.

39. Malmberg LP, Mäkelä MJ, Mattila PS, Hammarén-Malmi S, Pelkonen AS. Exercise-induced changes in respiratory impedance in young wheezy children and nonatopic controls. Pediatr Pulmonol. 2008;43:538-544.

40. Szefler SJ. Advances in pediatric asthma in 2008: where do we go now? J Allergy Clin Immunol. 2009;123(1):28-34.

41. Duong M, Subbarao P, Adelroth E, et al. Sputum eosinophils and the response of exercise-induced bronchoconstriction to corticosteroid in asthma. Chest. 2008;133(2):404-411.

42. Hsieh CC, Goto H, Kobayashi H, Chow WC, Peng WH, Tang RB. Changes in serum eosinophil cationic protein levels after exercise challenge in asthmatic children. J Asthma. 2007;44(7):569-573.

43. Beyden N, Davis SD, Lombardi E, et al. An official American Thoracic Society/European Respiratory Society statement: pulmonary function testing in preschool children. Am J Respir Crit Care Med. 2007; 175:1304-1345.

44. American Thoracic Society. Guidelines for methacholine and exercise challenge testing-1999. Am J Respir Crit Care Med. 2000;161: 309-329.

45. Leff, JA, Busse WW, Pearlman D, et al. Montelukast, a leukotrienereceptor antagonist, for the treatment of mild asthma and exerciseinduced bronchoconstriction. N Engl J Med. 1998;339(3):147-152.

46. Langdeau, JB, Day A, Turcotte H, Boulet LP. Gender differences in the prevalence of airway hyperresponsiveness and asthma in athletes. Respir Med. 2008;103(3):401-406.

47. Pohlig C. Exercise-induced bronchospasm coding and billing for physician services. Chest. 2009;135(1):210-214.

48. Kim JH, Lee SY, Kim HB, et al. Prolonged effect of montelukast in asthmatic children with exercise-induced bronchoconstriction. Pediatr Pulmonol. 2005;39(2):162-166.

49. Nishio K, Odajima H, Motomura C, Nakao F, Nishima S. Exhaled nitric oxide and exercise-induced bronchospasm assessed by $\mathrm{FEV}_{1}, \mathrm{FEF}_{25 \%-75 \%}$ in childhood asthma. J Asthma. 2007;44(6):475-478.

50. Tahan F, Karaaslan C, Aslan A, Kiper N, Kalayci O. The role of chemokines in exercise-induced bronchoconstriction in asthma. Ann Allergy Asthma Immunol. 2006;96:819-825.

51. Riccioni G, Bucciarelli T, Mancini B, Ilio CD, D’Orazio N. Antileukotriene drugs: clinical application, effectiveness and safety. Curr Med Chem. 2007;14(18):1966-1977.

52. Philip G, Pearlman DS, Villarán C, et al. Single-dose montelukast or salmeterol as protection against exercise-induced bronchoconstriction. Chest. 2007;132(3):875-883.

53. The World Anti-Doping Agency. The 2009 Prohibited List International Standard. Available from: http://www.wada-ama.org/. [Cited 2009 Jul 21].

54. Bonsignore MR, La Grutta S, Cibella F, Scichilone N, et al. Effects of exercise training and montelukast in children with mild asthma. Med Sci Sports Exerc. 2008;40(3):405-412.

55. Ternesten-Hasséus E, Johansson EL, Bende M, Millqvist E. Dyspnea from exercise in cold air is not always asthma. J Asthma. 2008;45: $705-709$.
56. Stensrud T, Berntsen S, Carlsen KH. Exercise capacity and exercise-induced bronchoconstriction (EIB) in a cold environment. Respir Med. 2007;101:1529-1536.

57. Lee SY, Kim HB, Kim JH, et al. Responsiveness to montelukast is associated with bronchial hyperresponsiveness and total immunoglobulin E but not polymorphisms in the leukotriene C4 synthase and cysteinyl leukotriene receptor 1 genes in Korean children with exercise-induced asthma (EIA). Clin Exp Allergy. 2007;37(10):1487-1493.

58. Bronsky EA, Kemp JP, Zhang J, Guerreiro D, Reiss TF. Dose-related protection of exercise bronchoconstriction by montelukast, a cysteinyl leukotriene-receptor antagonist, at the end of a once-daily dosing interval. Clin Phamarcol Ther. 1997;62(5):556-561.

59. Knorr B, Holland S, Schwartz J, Rogers JD, Reiss TF. Clinical pharmacology of montelukast. Clin Exp Allergy Rev. 2001;1(3): 254-260.

60. Scow DT, Luttermoser GK, Dickerson KS. Leukotriene inhibitors in the treatment of allergy and asthma. Am Fam Physician. 2007;75(1): 65-70.

61. Pearlman DS, van Adelsberg J, Philip G, et al. Onset and duration of protection against exercise-induced bronchoconstriction by a single oral dose of montelukast. Ann Allergy Asthma Immunol. 2006;97:98-104.

62. Singulair (montelukast sodium). Circular Number 9628414. Whitehouse Station, NJ: Merck and Co., Inc.; 1998-2007.

63. Pajaron-Fernandez M, Garcia-Rubia S, Sanchez-Solis M, GarciaMarcos L. Montelukast administered in the morning or evening to prevent exercise-induced bronchoconstriction in children. Pediatr Pulmonol. 2006;41:222-227.

64. Kim JH, Lee SY, Kim H, et al. TBXA2R gene polymorphism and responsiveness to leukotriene receptor antagonist in children with asthma. Clin Exp Allergy. 2007;38:51-59.

65. Kang MJ, Lee SY, Kim HB, et al. Association of $I L-13$ polymorphisms with leukotriene receptor antagonist drug responsiveness in Korean children with exercise-induced bronchoconstriction. Pharmacogenet Genomics. 2008;18(7):551-558.

66. de Benedictis FM, del Giudice MM, Forenza N, Decimo F, de Benedictis D, Capristo A. Lack of tolerance to the protective effect of montelukast in exercise-induced bronchoconstriction in children. Eur Respir J. 2006;28(2):291-295.

67. Philip G, Villarán C, Pearlman DS, Loeys T, Dass SB, Reiss TF. Protection against exercise-induced bronchoconstriction two hours after a single oral dose of montelukast. J Asthma. 2007;44: 213-217.

68. Villaran C, O’Neill SJ, Helbling A, et al. Montelukast versus salmeterol in patients with asthma and exercise-induced bronchoconstriction. J Allergy Clin Immunol. 1999;104(3):547-553.

69. Storms W, Chervinsky P, Ghannam AF, Bird S, Hustad CM, Edelman JM; for the Challenge-Rescue Study Group. A comparison of the effects of oral montelukast and inhaled salmeterol on response to rescue bronchodilation after challenge. Respir Med. 2004;98:1051-1062.

70. Steinshamn S, Sandsund M, Sue-Chu M, Bjermer L. Effects of montelukast and salmeterol on physical performance and exercise economy in adult asthmatics with exercise-induced bronchoconstriction. Chest. 2004;126(4):1154-1160.

71. Weinberger M. Long-acting $\beta$-agonists and exercise. J Allergy Clin Immunol. 2008;122(2):251-253.

72. Hancox RJ, Subbarao P, Kamada D, Watson RM, Hargreave FE, Inman MD. $\beta_{2}$-Agonist tolerance and exercise-induced bronchospasm. Am J Respir Crit Care Med. 2002;165:1068-1070.

73. Lecheler J, Pfannebecker B, Nguyen DT, et al. Prevention of exercisedinduced asthma by a fixed combination of disodium cromoglycate plus reproterol compared with montelukast in young patients. Arzneimittelforschung. 2008;58(6):303-309.

74. Peroni DG, Piancentini GL, Pietrobelli A, et al. The combination of single-dose montelukast and loratadine on exercise-induced bronchospasm in children. Eur Respir J. 2002;19:104-107.

75. Bramley A. Iralukast (Novartis AG). IDrugs. 1998;1(1):147-151. 
76. Coreno A, Skowronski M, Kotaru C, McFadden ER. Comparative effects of long-acting $\beta_{2}$-agonists, leukotriene receptor antagonists, and a 5-lipoxygenase inhibitor on exercise-induced asthma. J Allergy Clin Immunol. 2000;106(3):500-506.

77. Mastalerz L, Gawlewicz-Mroczka A, Nizankowska E, Cmiel A, Szczeklik A. Protection against exercise-induced bronchoconstriction by montelukast in aspirin-sensitive and aspirin-tolerant patients with asthma. Clin Exp Allergy. 2002;32:1360-1365.
78. Haverkamp HC, Dempsey JA, Pegelow DF, et al. Treatment of airway inflammation improves exercise pulmonary gas exchange and performance in asthmatic subjects. $J$ Allergy Clin Immunol. 2007;120(1):39-47.

\section{Publish your work in this journal}

The Journal of Asthma and Allergy is an international, peer-reviewed open-access journal publishing original research, reports, editorials and commentaries on the following topics: Asthma; Pulmonary physiology; Asthma related clinical health; Clinical immunology and the immunological basis of disease; Pharmacological interventions and

\section{Dovepress}

new therapies. Issues of patient safety and quality of care will also be considered. The manuscript management system is completely online and includes a very quick and fair peer-review system, which is all easy to use. Visit http://www.dovepress.com/testimonials.php to read real quotes from published authors.

Submit your manuscript here: http://www.dovepress.com/journal-of-asthma-and-allergy-journal 